\title{
Contracampo
}

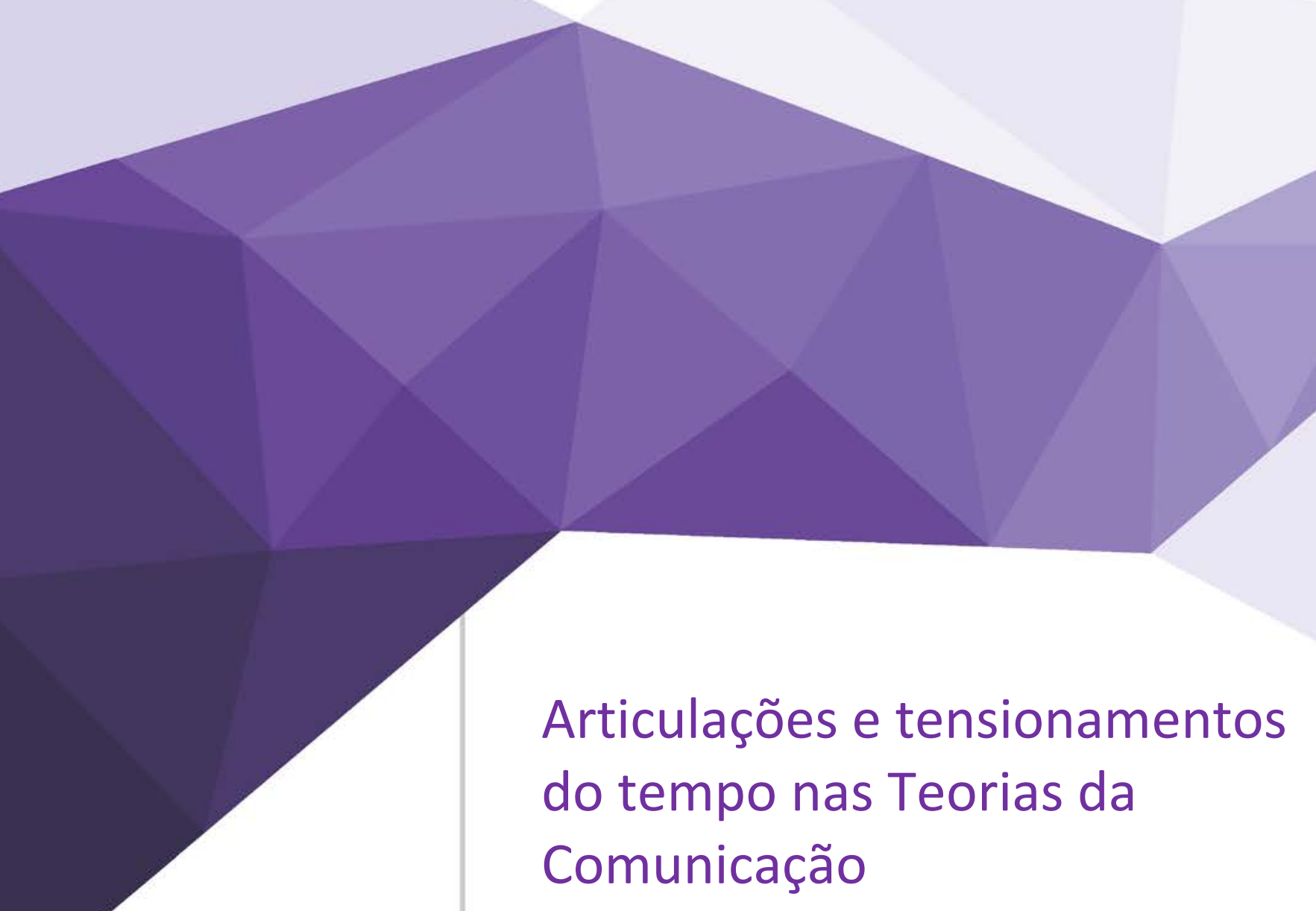

\section{Connections and tensions of}

time in Communication

Edição v.36

número 3 / 2017

Contracampo e-ISSN 2238-2577 Niterói (RJ), 36 (3)

dez/2017-mar/2018

A Revista Contracampo é uma revista eletrônica do Programa de Pós-Graduação em Comunicação da Universidade Federal Fluminense e tem como objetivo contribuir para a reflexão crítica em torno do campo midiático, atuando como espaço de circulação da pesquisa e do pensamento acadêmico.

\section{Theories}

\section{ÂNGELA CRISTINA SALGUEIRO MARQUES}

Professora do Programa de Pós-Graduação em Comunicação da Universidade Federal de Minas Gerais (UFMG), Belo Horizonte, Minas Gerais, Brasil. Doutora em Comunicação pela mesma universidade. Bolsista de Produtividade em Pesquisa do CNPq. Brasil. E-mail: angelasalgueiro@gmail.com. ORCID: 00000002-2253-0374

\section{LUIS MAURO SÁ MARTINO}

Professor do Programa de Pós-Graduação da Faculdade Cásper Líbero, na cidade de São Paulo, Brasil. Doutor em Ciências Sociais pela Pontifícia Universidade Católica de São Paulo (PUC-SP), São Paulo. Brasil. E-mail: Imsamartino@gmail.com. ORCID: 0000-0002-5099-1741.

\section{PPG COM arinedio UFF}

\section{AO CITAR ESTE ARTIGO, UTILIZE A SEGUINTE REFERÊNCIA:}

MARQUES, Ângela Cristina Salgueiro; MARTINO, Luis Mauro Sá. Articulações e tensionamentos do tempo nas Teorias da Comunicação. Contracampo, Niterói, v. 36, n. 03, pp. 177-198, dez. 2017/ mar. 2018. 


\section{Resumo}

O tempo, nos estudos de Comunicação, não é explicitamente problematizado em sua dimensão constitutiva dos fenômenos interacionais, ou, mais ainda, como variável de toda a ação e da própria existência. Nota-se, com muita frequência, sua apreensão enquanto variável histórica delimitadora de determinados aspectos da apreensão social das temporalidades. Em outras palavras, os estudos de Comunicação tendem a privilegiar o tempo como história, não como categoria analítica ou mesmo epistemológica. Este artigo tenta desenvolver uma visão específica a respeito das potencialidades e limites da presença do tempo nos processos comunicacionais. A partir de reflexão conceitual acerca de dimensões temporais presentes em certas Teorias da Comunicação, percebemos que o tempo é componente de destaque nas formulações teóricas, mas que seus aspectos específicos parecem diluir-se como uma dimensão entre outras dos fenômenos interacionais.

Palavras-chave

Teorias da comunicação; Tempo; Epistemologia.

\section{Abstract}

In Communication studies, time is not explicitly discussed as constitutive of interactional phenomena, or as a core variable of every action and of existence itself. It is frequently perceived as a historical variable delimiting specific aspects of the social apprehension of temporalities. In other words, Communication studies tend to privilege time in its historical aspect, not as analytical or epistemic category. This article is an attempt to develop a specific vision on the potentialities and limitations of the presence of time in communicative processes. From reflection on time dimensions in certain Communication Theories, we have found that time appears prominently in theoretical formulations, but its specific aspects seem to be considered as one dimension among others of the interactional phenomena.

\section{Keywords}

Communication Theories; Time; Epistemology. 


\section{Introdução ${ }^{1}$}

À primeira vista, quem procurar entender as relações entre tempo e comunicação tais como são apresentadas pelo corpo discursivo intitulado "Teorias da Comunicação" pode se deparar com uma ambiguidade. De um lado, nota-se a presença subjacente da questão temporal em quase todas as teorias - como todo fenômeno humano, a Comunicação acontece inscrita no tempo. Em alguns casos, essa vinculação é explícita, como nos estudos de História da Mídia e/ou da Comunicação, em coletâneas como no trabalho de Nunes (1998) ou nas obras organizadas por Ribeiro e Ferreira (2007) ou Freire Filho e Vaz (2006) ou o conjunto dos trabalhos apresentados no GT Memória nas Mídias, da Compós.

Nos espaços de formação de profissionais e pesquisadores, domínios da graduação e da pós-graduação, a apropriação do tempo nos estudos de Comunicação toma, sobretudo, uma forma disciplinar mais ou menos explícita. De um lado, a disciplina "História da Comunicação", que não raro se converte em uma História da mídia - e, portanto, um levantamento de seu desenvolvimento tecnológico sem necessariamente que se desenvolvam as variáveis sociais relacionadas - ou uma História das habilitações profissionais. O tempo, novamente, ocupa um lugar paralelo ao fenômeno, tematizado a partir de sua transformação em "passado".

No entanto, fora de uma perspectiva histórica ou de elaboração de memórias, o resultado é inverso: há poucos trabalhos que abordam o tempo como dimensão essencial às interações comunicativas e à constituição dos sujeitos e de seu viver "em comum". Note-se, por exemplo, a quase total ausência - uma exceção são os textos de Ferrara (2014) ou Marcondes Filho (2015) - desse tipo de abordagem nas discussões do GT Epistemologia da Comunicação, para mencionar outro espaço de diálogo acadêmico (MARTINO, 2014). Os "estados da arte" levantados, por exemplo, por Trumbo (2004), Bryant e Miron (2004), Sanchez e Campos (2009), assim como as taxonomias propostas por Lima (1983; 2001), Marcondes (2001) ou Torrico Villanueva (2004) e revistas por Martino (2015) não lidam com a questão do tempo em nenhum aspecto.

Certamente seria difícil, para não dizer impossível, falar de uma exclusão da variável "tempo" nas Teorias da Comunicação. Algumas linhas de investigação da Comunicação, como as mencionadas no início do texto, trazem em si a questão temporal como elemento importante, mas, novamente, em termos de sua transformação em alguma categoria relacionada - o arquivo, a memória, a

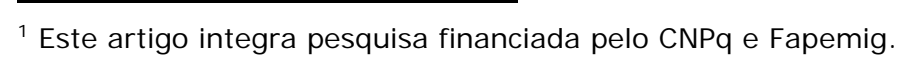


nostalgia. O tempo é, não raro, transformado em tempo passado, reelaborado no presente ou indicado como construção de um passado.

Em outra escala e modo de apropriação, nota-se que a questão do tempo ganhou uma breve proeminência dentro dos estudos de Internet e do ambiente das mídias digitais, quando as questões relacionadas às interações síncronas e assíncronas dentro das possibilidades de comunicação desses espaços passaram a ser pensadas como elementos relevantes para se compreender a Comunicação (PETERS, 2003; PRIMO, 2008).

Essas modalidades evidentemente não esgotam as apropriações e utilizações do tempo nas Teorias da Comunicação, mas indicam de alguma maneira como são as apropriações do tempo dentro da Área - e, sobretudo, o espaço dessa articulação.

Em termos epistemológicos, as Teorias da Comunicação desenvolvem-se evidentemente dentro de apropriações temporais, como tudo o que existe, mas raramente chegam a pensar qual é o peso que esse fator propriamente tem.

Em linhas bastante gerais, quando se fala nas relações entre "tempo" e "comunicação", no espaço das elaborações teóricas, o que mais se encontra é o desenvolvimento do pensamento comunicacional ao longo do tempo cronológico, e não o posicionamento do tempo nesses estudos - o que pode ser visto, por exemplo, em obras dedicadas à historiografia dos conceitos e teorias da Comunicação. O tempo, aqui, torna-se sinônimo de demarcações limitadoras de certas perspectivas teórico-epistemológicas. Esse procedimento transborda os limites da discussão epistemológica para se ramificar em outros espaços.

No risco existente em qualquer generalização, é possível dizer que o tempo, nos estudos de Comunicação, não é explicitamente problematizado em sua dimensão constitutiva de fenômenos intersubjetivos, ou, mais ainda, como variável de toda a ação e da própria existência: não existe, por assim dizer, uma visão específica a respeito das potencialidades e limites da presença do tempo nos processos comunicacionais. Nota-se, com muita frequência, sua apreensão enquanto variável histórica delimitadora de determinados aspectos da apreensão social das temporalidades - em outras palavras, os estudos de Comunicação tendem a privilegiar o tempo como história ou dimensão ordenadora das experiências e eventos cotidianos, não como categoria analítica ou mesmo epistemológica.

Nas várias tradições dos estudos de processos comunicacionais, a variável e/ou dimensão do tempo, embora seja fundamental, parece não ocupar um espaço privilegiado no âmbito das discussões e operacionalizações. As modalidades de apreensão do tempo no fazer comunicacional, em particular no âmbito das Teorias 
da Comunicação, com exceções, quase nunca aparecem em primeiro plano, no sentido que pode ser percebido a respeito de outros elementos. $E$, no entanto, as questões vinculadas às temporalidades - em sua miríade de formas - efetivamente estão inscritas no centro de todo e qualquer processo comunicacional.

De fato, não seria de todo errado afirmar que a própria existência de um processo de comunicação implica, em termos lógicos, a presença de alguma temporalidade. Seja pensado em termos de uma "transmissão", seja como "compartilhamento", utilizando as variáveis de Lima (1983; 2001), a comunicação implica a existência de intervalos de tempo nos quais ela propriamente tem lugar. Ao que tudo indica, independentemente da premissa teórica utilizada para se pensar a Comunicação, o tempo deveria ocupar uma posição de destaque, apresentando-se muitas vezes como categoria heurística igualmente invisível e determinante para a compreensão de determinados fenômenos.

O presente estudo se concentra na problemática do tempo como questão epistemológica parcialmente estruturadora do pensamento a respeito da comunicação, tal como se apresentam no percurso histórico-historiográfico das Teorias da Comunicação, entendidas, no caso, como discursos teóricos que constituem o objeto de estudo deste trabalho. Procura-se, dessa maneira, observar a presença transversal dessa temática no âmbito do chamado 'cânone' das Teorias da Comunicação, tal como apresentado, entre outros, por Mattelart e Mattelart (1999), Martino (2009) ou França e Guimarães (2016), entre outros. Este estudo se abriga no âmbito de questionamentos epistemológicos feitos aos fundamentos dos discursos teóricos em circulação na Área (FERREIRA, 2014).

O objetivo deste texto, portanto, é delinear algumas relações entre o tempo e o pensamento teórico em Comunicação, trabalhando a partir de um duplo questionamento. Parece existir, nos estudos de Comunicação, uma paradoxal apropriação do tempo: a despeito de sua importância fundamental como elemento constituinte dos fenômenos comunicacionais, sua problematização dentro das vertentes epistemológicas da Área não alcança o mesmo grau de importância de outros elementos.

Esses aspectos, escolhidos como recorte, não esgotam efetivamente o assunto, mas apontam as linhas que serão seguidas aqui. No que se segue, buscase delinear dois aspectos contraditórios e complementares dessa relação. De um lado, busca-se observar de que maneira o conjunto das Teorias da Comunicação, entendido como um discurso teórico que, como outros discursos, não pode ser separado das condições históricas de sua criação mas, ao mesmo tempo, não se estabelece como simples decorrência disso, se organiza temporalmente em uma “História" elaborada a partir de critérios políticos e epistemológicos. 
Na sequência, observa-se em detalhe quatro dessas teorias, tendo em vista a particular importância da qual o tempo nelas se reveste. Se, como dito, em boa parte do pensamento teórico em Comunicação o tempo é uma variável invisibilizada no conjunto de outros postulados, há ao menos algumas elaborações teóricas "Teorias da Comunicação" - nas quais o tempo ganha proeminência enquanto temporalidade ou conjunto de temporalidades constituidoras dos processos interacionais.

\section{A problemática geral: a localização das Teorias da}

\section{Comunicação no tempo}

O exame das periodizações dos estudos de Comunicação, em particular no domínio das Teorias da Comunicação, apresenta-se como resultado a percepção de uma taxonomia responsável por posicionar, em termos de tempo cronológico, as regiões de um "passado" do pensamento teórico da Área, a partir do qual se poderiam estabelecer critérios para a delimitação do que pode ou não efetivamente ser estudado. É interessante observar que, se as percepções não elaboradas do cotidiano podem servir como indício, parece existir um sentido de "progresso", quando não francamente "evolucionista" na avaliação sub-reptícia das Teorias da Comunicação nos momentos de sua vinculação à duração de determinadas épocas.

A disposição histórica e a sistematização por épocas das Teorias da Comunicação muitas vezes se apresenta dentro de uma ordem que segue o desenvolvimento das mídias. Uma "história das teorias da Comunicação", nesse sentido, poderia ser chamada muito mais de uma "história do pensamento sobre os meios técnicos", uma vez que sua ordenação por épocas decorre muito mais dos avanços da técnica do que propriamente das possibilidades comunicacionais, em todos os seus vínculos sociais, abertos pela técnica.

Isso nos remete, de saída, à problemática da localização dos discursos no tempo. Em seu estudo historiográfico clássico, Lowenthal (2004) recorda uma diferença que fundamental para a elaboração teórica proposta aqui: há uma diferença entre "Tempo", "História” e "Passado". Em termos iniciais, seria possível definir sua tese como um indicador de que a apropriação do tempo pela história dirige-se para a construção de um passado. De saída, o autor abandona uma perspectiva metafísica da apropriação do tempo, delimitando seu espaço de discussão: a metafísica do tempo pertence à Filosofia e pode ser discutida, em seus inúmeros méritos, dentro desse âmbito. 
O que se busca dentro da História não é o tempo, mas a conversão desse tempo em um "passado" que se torne apreensível e inteligível aos olhos do presente. A História, nesse aspecto, não é especificamente a mediadora entre "passado" e "presente", mas entre "tempo" e "passado", compreendidos como categorias em permanente articulação tensional. Essa mediação, evidentemente, está ligada a uma miríade de variáveis existentes no processo de seleção, escolha e significação de elementos que efetivamente podem produzir um passado.

Em sua interpretação de Lowenthal (2004), Jenkins (2006) observa o contraste do olhar do historiador com o do sociólogo ou do geólogo: em termos epistemológicos, esses olhares diferentes a respeito de um mesmo espaço se caracterizam justamente pela especificidade de um determinado fazer científico, responsável pela apropriação da realidade dentro de um recorte definido que dialoga, mas não se sobrepõe com outros - as "linhagens" a que se refere Ferreira (2007).

A História, nesse aspecto, parece não trabalhar, explica Jenkins, senão com as possibilidades de reconstruir um passado no sentido de se atribuir algum tipo de significado a ele, identificando-o como algo que ultrapassa o fugidio da percepção para se estabelecer como categorias inteligíveis - a "época", o "período", a "duração" ou qualquer outra forma de classificação - o que efetivamente conduz a um outro ponto, a validade dessas classificações.

Enquanto processo cognitivo, recorda Garcia Gutierrez (2009), toda classificação se reveste de uma dupla face, apresentando-se ao mesmo tempo como indispensável para qualquer intelecção, mas igualmente responsável por criar delimitadores às vezes intransponíveis associados aos fatores históricos, econômicos, sociais e políticos que presidem, muitas vezes de maneira invisível, a formação dos critérios classificatórios. Assim, a transformação do tempo em passado não está livre das formações de poder existentes na mediação do discurso da História no qual essa conversão acontece.

Temos, portanto, uma tríade complementar para pensarmos a questão que alinha um problema da percepção que beira a metafísica - a questão da realidade do tempo - às possibilidades efetivas de sua apropriação pelo ser humano, existente quando o fluxo das temporalidades é convertido em eventos localizáveis e, de certa maneira, passíveis de uma determinada delimitação causal em seus termos de "começo" e "fim".

O "tempo" se faz apropriável enquanto duração, mas essa transformação parece ocorrer apenas ao custo de não se poder perceber nada fora da duração, invisibilizando o tempo. É nesse aspecto que se observa a entrada da variável da História: a construção hermenêutica das durações responsáveis pela delimitação 
dos acontecimentos e de sua disposição criada de acordo com outras categorias da própria História.

É nesse momento que o tempo, já convertido anteriormente em duração por conta das próprias limitações da percepção humana, passa por uma segunda ordem de transformação e é convertido em "passado", um conjunto de dados construídos a partir da História com os quais se pode, de fato, trabalhar. Dessa maneira, transita-se da problemática da percepção do tempo para sua operacionalização heurística como passado elaborado pela História.

No entanto, prossegue Lowenthal (2004), quase não nos damos conta desse tipo de passagem, preferindo, no cotidiano, buscar uma equivalência prática entre História e Passado, como se a relação entre ambos fosse não apenas direta, mas inevitável. É nesse sentido, argumenta, que esses dois fatores guardam uma relação de proximidade com o tempo sem necessariamente encontrar algum tipo de equivalência necessária entre todos. O tempo passado é acessível apenas pela via da História, o que significa dizer, ao mesmo tempo, que não existe um passado senão como tempo histórico, elaborado a partir das possibilidades que uma historiografia ou, talvez ainda mais, uma epistemologia da História possa reaver. Veremos adiante como Walter Benjamin se opõe a essa percepção da História como passado ordenado causalmente ao propor contemplá-la à contrapelo, ressaltando a dialética que relaciona passado, presente e futuro.

O passado se afirma, nesse caso, como uma forma de interpretação da história dependente de fatores que ultrapassam a questão específica do "tempo" como categoria de construção da realidade, apresentando-se como um elemento dependente da apreensão que dele é feita no presente. Não é por acaso que Hayden White (2005), nesse sentido, tende a levar essa possibilidade às últimas consequências ao postular que a História não parece se diferenciar de outras modalidades de criação textual, mas que, ao contrário, como todo discurso, obedece à linhas de força existentes para se chegar a uma invenção - o passado, localização dos eventos no tempo a partir das possibilidades abertas pelos métodos historiográficos.

O olhar para o passado, nesse ponto, se afirma, sobretudo, como um olhar para o que Guinzburg (2008) trabalhará como a ideia de "indícios" ou "vestígios" possíveis de serem encontrados desse passado e, mais ainda, que poderiam ser interpretados a partir de categorias elaboradas no presente. Assim, mesmo diante do "passado", ou dos indícios deixados pelo tempo na forma de documentos palavra empregada aqui em seu sentido de utilização comum na História - , o olhar é sempre um olhar do presente que vai inventar uma possibilidade de passado dentro de suas condições atuais. 
O tempo se apresenta, dessa maneira, dotado de certa materialidade documental que permite sua exploração e reconstituição dentro de uma perspectiva de apropriação cognitiva formada, ou ao menos facilitada, pelo que se denomina a "História". Não por acaso, pensar o tempo significa, como visto, pensar o passado e suas apropriações dentro dessa história. É dentro desse aspecto que se pode perguntar de que maneira o passado da pesquisa em Comunicação, tomando como recorte o desenvolvimento das Teorias da Comunicação, é ao mesmo tempo uma história da apropriação de temporalidades dentro do pensamento epistemológico da Área.

Assim, não seria errado dizer que, na Área, muitas vezes o que chamamos de uma "História das Teorias da Comunicação" ou nomes derivados, estando entre os mais famosos os livros de Mattelart e Matterlart (1999) e Miege (2004), não é senão uma história das técnicas e tecnologias de Comunicação, em um sentido quase linear, longe de qualquer apreensão propriamente dialética da história que permita trabalhar em suas relações para além da simples "invenção", "surgimento" ou "eclosão" das tecnologias.

Com isso, parece se perder não apenas o sentido da comunicação, para além de seu aspecto midiático-tecnológico, no tempo, mas também a própria maneira como as questões históricas e temporais se inscrevem no âmbito de um pensamento comunicacional, convertido, no caso, em um inventário das principais inovações tecnológicas e seu "impacto" ou "efeito" na sociedade.

Essa perspectiva de ênfase nos meios tecnológicos parece ser responsável, ao menos em parte, pelo caráter de "evolução" pensado em relação ao desenvolvimento das Teorias da Comunicação: as teorias "antigas", localizadas em um tempo histórico construído a partir de uma variável midiática, quando não midiacêntrica, efetivamente se encontrariam superadas pelas teorias "novas", elaboradas a partir de igualmente "novas" mídias e, portanto, destinadas a invalidar, em termos lógicos e epistemológicos, o que havia sido feito até então.

Nesse sentido, o potencial hermenêutico de uma Teoria da Comunicação passa a ser julgado não mais por suas possibilidades heurísticas em relação ao presente, mas apenas em termos de sua criação temporal: teorias "antigas" explicam mídias "antigas" e, portanto, não têm validade na época de mídias "novas" que demandam, por sua vez, teorias "novas".

Herbst (2008) localiza a pesquisa em Comunicação dentro de uma perspectiva temporal. Em sua visão, as transformações históricas e culturais não deixam dúvida quanto à necessidade de se pensar, igualmente, o conjunto das teorias da Comunicação. No entanto, sua concepção é mais em termos de formação de uma área do que no fechamento histórico desta ou daquela teoria - limitação 
sugerida também por Demers (2000). A perspectiva de circunscrição histórica está igualmente presente, por exemplo, em Carlsson (2007) e Lebesco (2007).

O problema, ao que tudo indica, é que epistemologicamente a relação entre a empiria e o escopo teórico não obedece à linearidade esboçada aqui, mas sobretudo a uma complexa dialética de relações entre discursos, saberes, técnicas e práticas sociais na qual diversas épocas e temporalidades midiáticas convivem, e mesmo as mídias "novas" não destituem ou invalidam completamente as "antigas", mas se tensionam em práticas e ambientes sempre contemporâneos (FERRARA, 2013; 2014).

Dessa maneira, a ênfase nos aspectos midiáticos como forma de classificação parece sugerir, para além de uma questão apenas tecnológica, a perspectiva de que o alcance epistemológico de uma teoria da Comunicação está delimitado de acordo com sua época de formulação e, principalmente, em referência ao "meio" ao qual ela está atrelada.

A duração da "época" estaria vinculada a uma constante transformação em artefato arqueológico de tudo o que não seja imediatamente útil para a "explicação" do presente que, caminhando na velocidade das inovações tecnológicas definidas por uma lógica de mercado em termos de produção e descarte, tende a transformar as próprias teorias em elementos igualmente descartáveis.

Jensen e Neuman (2013) trabalham em termos da "evolução" da Área e das "mudanças de paradigma", em uma trilha vista anteriormente, entre outros, por França (2001), mas com poucos questionamentos a respeito da permanência ou potência explicativa de cada modelo. McQuail (2013), nesse sentido, agrega outro elemento de discussão ao problematizar até que ponto é possível, de fato, falar em "mudanças de paradigma" nas teorias e pesquisas em Comunicação em razão da história, relativamente recente, da Área.

Esse tipo de pensamento talvez possa ser um dos elementos para a compreensão da avidez com que conceitos oriundos de diversas áreas do saber, e que se apresentam como a última palavra em termos de explicação dos fenômenos comunicacionais ou de seus correlatos, são incorporados rapidamente ao vocabulário da Área de Comunicação. Tal movimento é feito, não raro, com pouca preocupação de um exame epistemológico mais amplo desses conceitos com vistas ao desdobramento de seu potencial heurístico, apenas para serem deixados de lado no momento da próxima inovação - não teórico-conceitual, mas técnica ou mercadológica.

Evidentemente isso não significa supor qualquer tipo de descontinuidade entre as Teorias da Comunicação e o ambiente midiático no qual elas foram ou são formuladas. Ao contrário, procura-se exatamente destacar que, se a validade de 
uma teoria também está ligada a um fator temporal, é necessário notar que as construções do tempo, transformado em história, se localizam dentro de classificações que podem ser questionadas e ampliadas com vistas a incluir não apenas o "meio", mas também as condições históricas de aparecimento desses meios e as apropriações teóricas correlatas. O determinismo tecnológico assinala-se também na manutenção de concepções a respeito de um tempo histórico que seria delimitado e delimitável, sem que se levem em conta as linhas de continuidade, por mais acidentadas que sejam, responsáveis pelas ressonâncias de épocas anteriores.

Não é por acaso que, quando se busca o caminho inverso, isto é, considerar em que medida as Teorias da Comunicação se apresentam dentro de uma dinâmica temporal e epistemológica própria, é possível observar uma série de movimentos não lineares, de apropriações e reapropriações das mais complexas, que não obedecem a nenhum tipo de elaboração passível de ser aproximada com a "ciência normal": não se pode, nesse aspecto, deixar de retomar Braga (2014), quando ele afirma, justamente, que "não há ciência normal em Comunicação".

Um exemplo possível, destacado em outro momento (BARROS e MARTINO, 2003; MARTINO, 2008; 2010), é o percurso das ideias de McLuhan dentro da Área de Comunicação, oscilando entre uma violenta crítica em meados dos anos 1980 até o início dos anos 2000, quando transformações sociais e tecnológicas parecem ter exigido uma retomada de seu pensamento com vistas à compreensão dos cenários que se apresentavam como desafios aos estudos da Área (LEMOS, 2007; PEREIRA, 2012). Essa retomada, assim como a permanência contemporânea de teorias "antigas" - como, por exemplo, a Escola de Frankfurt por Rüdiger (2005), Duarte (2010) ou Rodrigues e Martino (2011) -, sugere a mescla de tempos como formas de compreensão do contemporâneo para além de qualquer classificação de época.

A inscrição da Teorias da Comunicação no tempo parece se dar, entre outros fatores, a partir da transformação do tempo em passado nos caminhos da História - no caso, uma história das Teorias responsável pela elaboração das potencialidades de compreensão de fenômenos comunicacionais para além das tecnicidades midiáticas.

\section{A problemática do tempo em quatro teorias da}

\section{Comunicação}

No que se segue, apresentamos, de maneira não exaustiva e panorâmica, algumas evidências de que o tempo pode ser encontrado em algumas vertentes 
teóricas da Comunicação, sem que ele se manifeste de forma contundente ou como parte do argumento central das reflexões epistemológicas. É preciso localizá-lo e nomeá-lo a partir das entrelinhas.

\subsection{O tempo da ação situada e a antecipação das ações do interlocutor}

No interacionismo simbólico é possível dizer que o tempo pode ser considerado a partir de duas formas de ação específicas: a temporalidade que marca a produção de um encontro face a face e a duração desse encontro; e a temporalidade presente no modo como, a partir da leitura dos gestos significantes uns dos outros (MEAD, 2006), os agentes enunciadores exercem mútua influência (ação reciprocamente referenciada de Mead) aprendendo a interpretar e antecipar (por meio de um quadro compartilhado de expectativas) seus movimentos e posicionamentos performáticos.

Há, assim, por exemplo, uma temporalidade presente nas reflexões de Goffman (1999), que constrói uma sociologia das interações na tentativa de apreender e analisar não o homem em seus momentos, mas os momentos e seus homens. Os momentos que o interessam são aqueles que se apresentam no espaço-tempo das interações cotidianas ordenadas e guiadas por padrões de conduta. "O caráter ordenado das interações é reconhecido a partir de uma extensa base de pressuposições cognitivas partilhadas e de constrangimentos automantidos ou mesmo pressuposições normativas" (GOFFMAN, 1999, p.202).

O modo como os interlocutores se relacionam uns com os outros na reflexão de Goffman nos revela como uma temporalidade específica age sobre as trocas: o caráter ordenado e recorrente das interações permite aos atores conhecer antecipadamente os limites que constrangem seus modos de ação, criando expectativas de adequação dos comportamentos dentro dos limites identificados. Antecipar, na leitura situada, os gestos dos outros para construir uma resposta social adequada é uma forma de "prever" (e com isso muitas vezes cercear as possibilidades de agência do outro) o futuro e, com isso, tentar controlá-lo. Todavia, por mais que os interlocutores tentem controlar a situação e o comportamento de seus pares, há uma fragilidade, precariedade e instabilidade existentes nas interações e o enorme potencial de ruptura que circunda e ameaça constantemente as relações interacionais (MARTINS, 2008).

Para Goffman (1999), os gestos significativos dos interlocutores podem sersimulados graças à presença de sanções positivas ou recompensas, ou sanções 
negativas e punições, sendo que a definição das sanções está ligada a uma aprovação ou desaprovação imediatamente expressa e sentida na interação.

Nessa afirmação podemos elencar a convivência constante de duas temporalidades no pensamento de Goffman sobre as interações: o futuro sempre antecipado das simulações de comportamento dentro do previsto e a imediaticidade do julgamento de tal comportamento como adequado ou não às expectativas associadas a uma dada situação (ações reguladas diante do que é momentaneamente significativo para os sujeitos). Como ressaltam Martins (2008) e Gastaldo (2008), os atores sociais conduziriam suas vidas entre um exercício de antecipação das consequências de suas ações, procurando a todo custo evitar situações de embaraço que podem corroer as imagens projetadas de si mesmos e, eventualmente, conduzi-los à ruína e ao descrédito social.

Nas interações verbais face a face, distintas temporalidades se entrelaçam na tentativa de definir as situações, os temas e as formas de engajamento dos sujeitos em comunidade. A negociação comum da situação atual na qual se encontram os parceiros da interação firma o aspecto do "aqui e agora" que aproxima os sujeitos em sua busca pela produção de sentidos para as experiências vivenciadas. Mas os interlocutores constroem seus agenciamentos e suas performances em temporalidades diversas entre si e com relação à configuração imediata do "aqui e agora". Assim, é possível dizer que é no cruzamento dessas temporalidades que se articula um processo relacional e intersubjetivo contínuo, no qual a atitude de um sujeito frente a si mesmo emerge em seu encontro com a atitude do outro frente a ele.

Dito de outro modo, enquanto atuam no mundo de forma intersubjetiva, os indivíduos se constituem como atores sociais e sujeitos políticos que buscam reforçar seus laços de pertencimento a um grupo, ao mesmo tempo em que buscam o reconhecimento social de seu status moral como interlocutor legítimo.

\subsection{O tempo e a constituição comunicacional de sujeitos políticos}

A atividade política requer, na perspectiva do pragmatismo, uma situação de interlocução em que os sujeitos não só produzam um espaço partilhado e comum de trocas, mas também instaurem uma temporalidade dedicada à reflexão e à justificação públicas. Um sujeito político é aquele que tem tempo para falar e, já na interação, tem um tempo de fala alargado, que o permita construir, expressar e rever seus pontos de vista. Em Goffman estão presentes várias metáforas espaciais 
(cena, fachada, fundo, situação, etc.) responsáveis por caracterizar o encontro interlocutivo, a performance $e$ as tensões provocadas pela adequação e readequação de comportamentos às normas e quadros de sentido. Mas se há uma multiplicidade de espaços, há também uma multiplicidade de tempos cuja distribuição desigual entre os atores sociais descortina relações de poder e opressão.

Em John Dewey (2008), a política se manifesta a partir de um processo de formação de públicos que se constituem enquanto tais quando têm que lidar com uma questão controversa tematizada como problema público. Tal tipo de problema adquire uma dimensão ampliada não só por afetar muitas pessoas, mas também por exigir um tipo de reflexividade social que guia a ação coletiva. Assim, um problema público e os públicos que o definem surgem simultaneamente, instaurando um tempo e um espaço marcados pela tentativa de construir vínculos de associação e cooperação capazes de nortear ações comunicativas destinadas a melhor entender e/ou solucionar problemas de interesse coletivo. A sincronicidade do "aparecer" dos públicos e de seus problemas é algo que merece nossa atenção, uma vez que "a principal dificuldade é descobrir os meios pelos quais um público disperso, inconstante e múltiplo possa se reconhecer de forma a definir e expressar seus interesses" (DEWEY, 2008, p.54).

Segundo Dewey, um público é formado por todos aqueles que se veem afetados pelas consequências indiretas das transações e trocas comunicativas voltadas para a tematização e elucidação de problemas coletivos. Mas "o mesmo público não existe em dois momentos ou lugares. As condições situacionais tornam diferentes as consequências da ação associada e do conhecimento delas" (Dewey, 2008, p.34). Um público é fruto de sua ação localizada num tempo e num espaço específicos, sendo que seus interesses e demandas são fruto da associação, do intercurso e da interpelação. "Os afetados de maneira indireta e séria, para o bem ou para o mal, formam um grupo que é distinto e passa a exigir um reconhecimento e um nome: o Público." (DEWEY, 2008, p.49)

As ações e movimentações dos públicos nos espaços públicos de interação e discussão existem como signos ${ }^{2}$, como sinais ou símbolos que se relacionam e constituem articulações e memórias permitindo que uma série de eventos seja registrada e preservada como significado. Os públicos possuem, então, repertórios que Ihes permitem recordar agências passadas, prever e calcular rotas de ações

\footnotetext{
2 É importante destacarmos que a semiótica de Peirce também possui uma dimensão temporal relacionada aos três modos de apreensão dos fenômenos do mundo pela mente: a primeiridade, a secundidade e a terceiridade são categorias de apreensão dos fenômenos que se estruturam, respectivamente, a partir do tempo de contemplação (afetação do puro sentir), do tempo envolvido na operação de distinção e choque entre elementos pela lei da ação e reação, e do tempo destinado à produção de uma síntese inteligível do fenômeno via pensamento (ou seja, sua tradução em signo).
} 
futuras, facilitando "o cálculo, o planejamento e um novo tipo de ação que intervém no que acontece a fim de direcionar seu curso para o interesse do que é previsto e desejado" (DEWEY, 2008, p.58). Nesse sentido, os públicos são formas de experiência.

Aqui é oportuno lembrar que a reflexão de Dewey sobre a significação da experiência atravessa toda a sua obra e possui uma forte dimensão temporal. A experiência é apresentada como o estabelecimento de uma ligação entre aquilo acerca do qual se faz uma experiência e a maneira pela qual uma experiência é conduzida: entre um objeto e um sujeito. A dimensão temporal da experiência está presente no próprio movimento instaurado entre sujeito e objeto, em uma relação mútua. Para Dewey, "a experiência constitui-se de um material cheio de incertezas, movendo-se em direção a sua consumação através de uma série de vários incidentes" (2005, p.95). A profundidade da experiência é dada pela relação entre a experiência atual e a passada, por meio de conexões entre o que já foi feito e o que se deve fazer em seguida. "Em uma experiência o fluxo vai de algo a algo. Como uma parte conduz a outra e como outra parte traz aquela que veio antes, cada uma ganha distinção em si própria. O todo permanente é diversificado por fases sucessivas que constituem ênfases de seus variados matizes" (2005, p.90). Uma experiência é fruto de um processo de organização temporal em que "a chegada ao final" está relacionada a tudo o que aconteceu antes enquanto culminância de um movimento contínuo. O trabalho que une as parcelas de uma experiência se manifesta no desenvolvimento de um "enredo, que depende de um cenário, de um espaço onde desenvolver-se e um tempo para desdobrar-se" (2005, p.95).

Experiência é movimento, ritmo, cadência com várias velocidades dentro de uma velocidade, entrelaçando movimento e encadeamento temporal de fatos. Devido a seu contínuo ressurgir, menciona Dewey, não há brechas ou hiatos quando temos uma experiência. Há pausas, lugares de descanso, mas elas pontuam e definem a qualidade do movimento. "Resumem o que se passou e evitam sua dissipação e sua vã evaporação. Sua aceleração é contínua, de modo que evita a separação das partes" (2005, p.90). As pausas da experiência se relacionam a um constante padecer, "em que são absorvidas e abrigadas as consequências de um fazer anterior e cada fazer traz em si próprio um significado que foi extraído e conservado" (2005, p.105). As várias partes de uma experiência estão ligadas umas às outras e não apenas sucedem umas a outras, de modo que o resultado é sempre antecipado a cada momento e periodicamente apreciado com especial intensidade.

O conceito de experiência e de públicos em Dewey, assim como as noções de agência reciprocamente referenciada e "outro generalizado" em Mead assumem 
lugar proeminente no pensamento da segunda geração da Teoria Crítica, especialmente em Habermas. As temporalidades da experiência e da elaboração de problemas públicos configuram, em Habermas, um modelo de democracia que concebe a política não como processos que ocorrem somente no âmbito das instituições, mas como redes de comunicação que se configuram no cotidiano, em meio às negociações intersubjetivas de normas, valores, crenças, interesses e entendimentos que os atores realizam em um determinado contexto social situado em um tempo e um espaço específicos.

\subsection{O tempo entre trabalho e lazer na Teoria Crítica}

$\mathrm{Na}$ Teoria Crítica a questão do tempo pode ser tematizada a partir de duas constatações feitas por Adorno e Horkheimer. A primeira refere-se a uma espécie de dilatação ou distensão do presente para que ele comporte todo o impulso consumista alimentado pelo conformismo e pela repetição constante das mesmas fórmulas e incitações. "O conformismo dos consumidores se satisfaz com a reprodução do sempre igual. A Indústria cultural consiste na repetição" (Adorno e Horkheimer, 2002, p.27). "A reprodução do sempre igual" remete a uma invariabilidade temporal que instaura uma rotina consensual propícia tanto à diluição de conflitos, quanto ao apagamento das fronteiras entre trabalho e lazer. 0 tempo presente, dilatado pela indústria cultural, afirma que as necessidades e desejos devem ser supridos "aqui e agora", de modo que a diversão seja percebida como prolongamento do trabalho. Nesse sentido, a segunda constatação é a de que aquilo que se consome como entretenimento no tempo destinado ao lazer é uma cópia do processo de trabalho, uma sucessão automática de operações reguladas.

Com essa contiguidade entre o tempo de trabalho e o tempo de lazer surgem novos ritmos de existência e também de domesticação dos sentidos. É conhecida de todos a crítica feita em Dialética do Esclarecimento às mensagens de diversão da indústria cultural: "Se os desenhos animados têm outro efeito além de habituar os sentidos a um novo ritmo, é o de martelar em todos os cérebros a antiga verdade de que o mau trato contínuo, o esfacelamento de toda resistência individual, é a condição da vida nesta sociedade"(1983, p.33).

Há assim, duas temporalidades que esmagam o sujeito e suas possibilidades de resistência: uma que o faz viver no presente todo o tempo de modo a acompanhar as novidades e apelos ao consumo; e outra que, ao diluir o lazer com o trabalho rouba o tempo necessário à reflexão e elaboração sobre fatos e experiências passadas, assim como desmobiliza os planos para o futuro e o planejamento de ações de mudança no presente. Além disso, a própria regulação 
dos tempos de trabalho e de ócio determina os modos como cada sujeito vai se ocupar de atividades e ações, como cada um vai se posicionar e ser posicionado nos espaços destinados ao comum, à produção de decisão política e à participação pública. A atividade reflexiva e crítica requer uma desaceleração do tempo, para que o olhar se habitue novamente à contemplação e não somente à imediaticidade dos flashes luminosos dos anúncios de mercadorias.

Sob esse aspecto, os mecanismos de funcionamento e reprodução da indústria cultural evidenciam uma divisão entre os que vivem o tempo da ação e do conhecimento reflexivo e aqueles que vivem o tempo da sobrevivência, da alienação e da repetição. Com suas necessidades e desejos previstos, forjados e automaticamente supridos, os indivíduos permanecem mais tempo como consumidores, como objetos da indústria cultural, do que como espectadores emancipados. O tempo aqui é operador de exclusões e assimetrias diversas, atuando, juntamente com a cultura transfigurada em mercadoria, como obstáculo à emancipação e à autonomia. A crítica marxista presente nessa distribuição desigual dos tempos e das possibilidades de expressão entre os sujeitos e grupos está centralmente presente na abordagem filosófica de Jacques Rancière ( $A$ partilha do sensível), por exemplo, e, mais recentemente em sua interlocução com Axel Honneth (A luta por reconhecimento). ${ }^{3}$

\subsection{A legibilidade temporal das imagens dialéticas}

Uma outra abordagem do tempo no escopo da Teoria Crítica pode ser encontrada no pensamento de Walter Benjamin e em suas interfaces com a memória e a História. Em Benjamin, o gesto de rememoração produz imagens, formas de ler o tempo e modos de fazer saltar o dispositivo consensual que organiza linearmente e causalmente passado, presente e futuro. Sob esse prisma, a imagem dialética, segundo ele, nos leva a compreender de que maneira os tempos se tornam visíveis e passíveis de alimentar maneiras de imaginar e produzir política.

De acordo com Michel Löwy a imagem dialética expressa o fato de que "a relação entre hoje e ontem não é unilateral: em um processo eminentemente dialético, o presente ilumina o passado, e o passado iluminado torna-se uma força no presente" (LÖWY, 2005, p.61).

\footnotetext{
${ }^{3}$ O rico debate entre Rancière e Honneth encontra-se organizado na obra: GENEL, Katia; DERANTY, J ean-Phillipe (eds). Recognition or Disagreement: a critical encounter on the politics of freedom, equality and identity. Columbia University Press, 2016.
} 
Essa definição, segundo Gagnebin (1999, p.15), “coloca em questão uma representação abstrata e vazia do tempo histórico como sucessão infinita de pontos que somente a ordem de sua aparição interligaria". Os fenômenos históricos seriam, assim, fruto dessa tensão dialética entre passado, presente e futuro, assumindo a forma de uma constelação. Fenômenos históricos, isolados como estrelas no céu, só adquirem sentido quando um trabalho de rememoração e montagem produz um traçado que reúne o presente e o passado. Para Gagnebin (1999, p.16), a exigência de rememoração do passado "não implica simplesmente a restauração do passado, mas também uma transformação do presente tal que, se o passado perdido aí for reencontrado, ele não fique o mesmo, mas seja, ele também, retomado e transformado".

“A imagem benjaminiana nos é apresentada, portanto, enquanto forma de legibilidade do tempo" (LÖWY, 2005, p.131), uma vez que ela não só se produz no encontro de temporalidades diversas, mas também cruza temporalidades em lampejos, em luzes que cortam e iluminam esporadicamente o horizonte totalitário e consensual que geralmente organiza as experiências.

Como nos esclarece Didi-Huberman, a imagem dialética não é uma imagem na acepção denotativa do termo, mas uma metáfora para um dispositivo que faz surgirem e sobreviverem os "momentos inestimáveis" que resistem a capturas, silêncios e aos excessos de discursos construídos midiaticamente e pelo Estado. Por isso, ele constrói a hipótese (2011, p.119) de que a imagem é um operador temporal de sobrevivências, portadora de uma potência política relativa a nosso passado, presente e futuro.

A noção de imagem dialética nos permitiria perceber a temporalidade de gestação dos contrapoderes, "ver o ritmo dos golpes e contragolpes, tempos e contratempos, temas e contratemas, aclamações e revoluções" (DIDI-HUBERMAN, 2011, p.110).

A temporalidade impura de nossa vida histórica é resultado do esboço de uma ligação inédita entre dois fenômenos (ou mais) que adquirem um novo sentido e desenham um novo objeto histórico, até aí insuspeitado, mais verdadeiro e mais consistente que a cronologia linear (GAGNEBIN, 1999). Em oposição à narração que enumera cronologicamente a sequência dos acontecimentos, este procedimento, que faz emergir momentos privilegiados para fora do continuum cronológico, é definido, no fim das Dez Teses sobre a História, como "a apreensão de uma constelação salvadora". O tempo na imagem dialética opera também como operador de montagem e desmontagem no gesto político de "acolher o descontínuo da história, de proceder à interrupção desse tempo cronológico sem asperezas, 
renunciando ao desenvolvimento feliz de uma sintaxe lisa e sem fraturas" (GAGNEBIN, 1999, p.99).

A imagem dialética subverte o ordenamento consensual e naturalizante do discurso estabelecido e exige de nós uma preocupação constante com o futuro, recusando uma desmobilização pela nostalgia do passado. I sso porque, para ele, "o verdadeiro objeto da lembrança e da rememoração não é, simplesmente, a particularidade de um acontecimento, mas aquilo que, nele, é criação específica, promessa do inaudito, emergência do novo" (GAGNEBIN, 1999, p.105). A rememoração é gesto criador e transformador que abre espaço para a construção ativa e constante do presente.

\subsection{As temporalidades do devir minoritário}

A reflexão construída por Gilles Deleuze acerca da imagem cinematográfica comporta e é articulada pela noção de tempo. Mas seu encontro com Félix Guattari promove uma abordagem do tempo que nos parece instigante e que está assim anunciada: "acreditar no mundo significa principalmente suscitar acontecimentos, mesmo pequenos, que escapem ao controle, ou engendrar novos espaços-tempos, mesmo de superfície ou volume reduzidos" (DELEUZE, 2013, p.222). Por meio desse enunciado, Deleuze articula a noção de devir minoritário com as práticas de resistência e existência de sujeitos políticos. Tal movimento interessa à Comunicação não só pela proposição espaço-temporal associada à constituição mundos possíveis, mas também porque o devir minoritário opera através da criação de enunciados e modos de enunciação que possibilitam a emergência do "ser em comum em cooperação".

A constante tensão e passagem entre maioria/minoria, molar/molecular marca uma recusa a identidades sociais que aprisionam, e uma busca pelos territórios existenciais não sujeitos a um princípio majoritário. Assim, o devir minoritário revela a produção da multiplicidade em ato, a invenção de um vir a ser autônomo, imprevisto, produtor de agenciamentos moleculares da multiplicidade. Tais agenciamentos, de acordo com a apropriação que Maurizio Lazzarato (2007) faz de Deleuze, procuram experimentar dispositivos, criar instituições que sejam mais favoráveis às dinâmicas de criação e atualização de mundos possíveis.

Criar passagens problematizantes entre o molar e o molecular, a maioria e a minoria traria condições para a transformação e experimentação das relações de poder que constituem esses pares. Mas é preciso lembrar que transitar "entre", significa encontrar temporalidades, velocidades e ritmos de produção de linhas de fuga que impeçam o molar de se fechar em modelos majoritários, e façam do 
molecular a fonte de processos de criação e de subjetivação (LAZZARATO, 2007). A produção do "entre", das passagens e dos trânsitos, presente também em Benjamin, cria condições para a transformação e a experimentação das relações de poder que produzem subjetividade e diferença. O devir minoritário atualiza a virtualidade das relações fluidas e reversíveis, abertas à experimentação de subjetivações que escapam aos estados de dominação. Essa é a base filosófica que tem alimentado a reflexão, no campo da Comunicação, acerca das insurgências e sublevações que tomam ruas e redes no Brasil, como o movimento secundarista e as Jornadas de Junho de 2013 (ALTHEMAN, MARQUES e MARTINO, 2017; SILVA, 2014).

Essa tentativa de explicitar algumas dimensões temporais em certas Teorias da Comunicação nos revela que o tempo é componente de destaque nas formulações conceituais, mas que seus aspectos específicos, na ausência de problematização devida, parecem diluir-se como uma dimensão entre outras dos fenômenos interacionais.

\section{Referências}

ADORNO, Teodor; HORKHEIMER, Max. O iluminismo como mistificação das massas. In: I ndústria Cultural e Sociedade. São Paulo: Paz e Terra, 2002.

ADORNO, Teodor; HORKHEIMER, Max. Dialética do Esclarecimento. Rio de J aneiro: Jorge Zahar, 1983.

ALTHEMAN, Francine; MARQUES, Angela; MARTINO, L. M. Comunicação nos movimentos insurgentes: conversações políticas on-line durante a ocupação de escolas em São Paulo. In: VII Compolítica, 2017, Porto Alegre. Anais do VII Compolítica. Porto Alegre: Fabico, 2017. v. 1. p. 1-25.

BRAGA, José Luiz. Um conhecimento aforístico. Texto apresentado no $\mathbf{2 3}^{\circ}$ Encontro Anual da Compós. Belém, 23 a 26 de junho de 2014.

BRYANT, Jennings; MIRON, Doriana. Theory and Research in Mass Communication. J ournal of Communication. December 2004/Vol. 54 n. 4.

CARLSSON, Ulla. Media and Mass Communication Research Past, Present and Future. Nordicom Review, Jubilee Issue 2007, pp. 223-22.

DELEUZE, Gilles. Conversações. São Paulo: Ed. 34, 2013.

DEMERS, David. Communication Theory in the 21st Century: Differentiation and Convergence. Mass communication and society, n. 3, Vol. 01, 2000, pp. 1-2.

DEWEY, John. DemocraciaCooperativa: escritos políticos escolhidos de John Dewey, 1927-1939. Porto Alegre: EDIPUCRS, 2008.

DEWEY, John. A arte como experiência (Tendo uma experiência), p. 89-105. 
DEWEY, John. L'acte d'expression. In : .L'art comme expérience. Pau: Farrago, 2005.

DIDI-HUBERMAN, Georges. A sobrevivência dos vagalumes. Belo Horizonte: Editora UFMG, 2011.

DUARTE, Rodrigo. Teoria Crítica da Indústria Cultural. Belo Horizonte: Ed. UFMG, 2009.

FERRARA, Lucrécia D'Aléssio. A epistemologia de uma comunicação indecisa. Trabalho apresentado no $\mathbf{2 2}^{\circ}$ Encontro da Compós. Salvador, junho 2013.

FERRARA, Lucrécia. D'Aléssio. A comunicação: da epistemologia ao empírico. Trabalho apresentado no 23 Encontro da Compós. Belém, Maio de 2014.

FERREIRA, Jairo. Questões e linhagens na construção do campo epistemológico da Comunicação. In: (org.). Cenários, teorias e metodologias da Comunicação. Rio de Janeiro: e-papers, 2007.

FRANÇA, Vera. Paradigmas da Comunicação: conhecer o quê?. In: MOTTA, Luiz Gonzaga; FRANÇA, V., PAIVA, R. e WEBER, M. H. (orgs.) Estratégias e culturas da comunicação. Brasília: Editora UnB, 2001.

FRANÇA, Vera; SIMÕES, Paula. Curso Básico de Teoria da Comunicação. Belo Horizonte: Autêntica, 2016.

GAGNEBI N, J eanne Marie. História e Narração em Walter Benjamin. São Paulo: Ed. Perspectiva, 1999.

GARCIA GUTIERREZ, Antonio. Desclasificados. Barcelona: Anthropos, 2007.

GASTALDO, Édison. Goffman e as relações de poder na vida cotidiana. Rev. bras. Ci. Soc. [online]. 2008, vol.23, n.68 [cited 2013-04-22], pp. 149-153.

GOFFMAN, Erving A ordem da interação. In:

Os momentos e os seus homens. Textos escolhidos e apresentados por Yves Winkin. Lisboa: Relógio d’Água Editores, 1999.

GUI NZBURG, Carlo. Mitos, sinais, emblemas. São Paulo: Companhia das Letras, 2008.

HERBST, Susan. Disciplines, Intersections, and the Future of Communication Research. J ournal of Communication no. 58, Vol. 1, 2008, pp. 603-616.

JENKINS, Keith. Repensando a história. São Paulo: Contexto, 2006.

JENSEN, Klaus; NEUMAN, W. Russel. Evolving paradigms of Communication Research. I nternational J ournal of Communication no. 7, Vol. 1, 2013, pp. 230-240.

LAZZARATO, Maurizio. From the revolutions of capitalism. Substance, n. 112, v. 36, n. 1, 2007.

LEBESCO, Kathleen. Beyond the Second Media Age: Contemporary Communication Theory. Review of Communication, n. 7: Vol. 1, 2007, pp. 37-39.

LEMOS, André. Cibercultura. Porto Alegre: Sulina, 2007. 
LIMA, Venício. Mídia: teoria e pesquisa. São Paulo: Perseu Abramo, 2001.

LIMA, Venício. Repensando as teorias da comunicação. In: MELO, J. M. Teoria e pesquisa em comunicação. São Paulo, Intercom/Cortez, 1983.

LOWENTHAL, David. The past is a foreign country. Cambridge, Cambridge University Press, 2004.

LÖWY, Michael. Walter Benjamin: aviso de incêndio. SP: Boitempo, 2005.

MARTINO, Luis Mauro Sá. Descontinuidades epistemológicas na Teoria da Comunicação: um estudo das taxonomias entre 1969 e 2011. Logos, v.22, p.105 120, 2015.

MARTINS, Carlos Benedito de Campos. Notas sobre o sentimento de embaraço em Erving Goffman. Revista Brasileira de Ciências Sociais, 2008, vol. 23, n. 68, pp. 137-144.

MATTERLART, Armand.; MATTELART, Michele. História das Teorias da Comunicação. São Paulo: Loyola, 1999.

McQUAIL, Dennis. Reflections on Paradigm Change in Communication Theory and Research. International J ournal of Communication. n. 7, Vol. 1, 2013, pp. 216229.

MEAD, George Herbert L'esprit, le soi et la société. Paris: PUF, 2006.

MIEGE, Bernard. O pensamento comunicacional. Petrópolis: Vozes, 2004.

PEREI RA, Vinicius. Estendendo McLuhan. Porto Alegre: Sulina, 2013.

PETERS, John Durham. Space, time, and Communication Theory. Canadian Journal of Communication. Vol. 28, n. 1, 2003, pp. 397-411.

PRIMO, Alex. I nterações em Rede. Porto Alegre: Sulina, 2007.

RÜDIGER, Francisco. Teoria Social Crítica e Pesquisa em Comunicação. Porto Alegre: Ed. PUC-RS, 2005.

SÁNCHEZ, Lydia CAMPOS, Manuel. La Teoría de la comunicación: diversidad teórica y fundamentación epistemológica. Dialogos de La Comunicación. N. 78, JaneiroJulio 2009, pp. 24-38.

SILVA, Regina Helena Alves. Ruas e Redes: dinâmicas dos protestosBR. Belo Horizonte: Autentica Editora, 2014.

TORRICO VILLANUEVA, Erick. Abordajes y periodos de la teoría de la comunicación. Buenos Aires: Norma, 2004.

TRUMBO, Craig. Research methods in Mass Communication Research: a census of eight journals 1990-2000. Journalism and Mass Communication Quarterly, vol. 51, n. 02, Summer 2004, pp. 417-436.

WHITE, Hayden. Trópicos do Discurso. São Paulo: Edusp, 2005. 